\title{
Interventional Therapy for Pancreatic Cancer
}

\author{
Jianwei Zhu Zhendong Jin \\ Department of Gastroenterology, Changhai Hospital, Second Military Medical University, \\ Shanghai, China
}

\author{
Key Words \\ Endoscopic ultrasound · Endoscopy · Pancreatic cancer · Therapy
}

\begin{abstract}
Background: Palliative therapy and primarily chemoradiotherapy are the mainstream treatments in patients with locally advanced or metastatic pancreatic cancer (PC). Conventional endoscopy and endoscopic ultrasound (EUS)-guided interventional therapy has emerged as an important procedure for PC management. In this review, the progress in conventional endoscopy and EUS for PC management is discussed. Summary: For local palliative therapy against PC, EUS-guided fine needle injection (FNI) could deliver different kinds of agents, such as radioactive seeds and fiducials. Although their feasibility and safety have been proven, the long-term efficiency of EUS-FNI is still not established. For pain, EUS-celiac plexus neurolysis (CPN) is effective. However, CPN can only relieve the pain to a limited degree, with short duration. Endoscopy-guided stent placement is the preferred strategy for biliary and duodenal obstruction. Plastic and metal stents are equally effective for the relief of obstructive jaundice. The functional times of metal stents are longer than those of a plastic stent. Key Message: For biliary obstruction, a metal stent is the first choice. The long-term efficiency of EUS-FNI still needs further study. Practical Implications: Endoscopy and EUS-guided interventions have gradually become the mainstream method for local treatment of PC due to mini-invasiveness and real-time observation. PC is the second most common gastrointestinal malignancy and the sixth leading cause of cancer mortality in the United States, leading to about 4.0\% of all cancer deaths [Siegel et al: CA Cancer J Clin 2014;64:9-29]. The only curative approach for patients with PC is surgical resection, but unfortunately $80-90 \%$ of patients have a surgically inoperable disease, with $53 \%$ having local metastases at the time of diagnosis [Weinberg et al: Oncology (Williston Park) 2015;29:809-820, 886]. Therefore, palliative therapy and primarily chemoradiotherapy are the mainstream of treatment in patients with locally advanced or metastatic PC. Although overall survival has improved from 6 to $8.5-11$ months
\end{abstract}


Zhu and Jin: Interventional Therapy for Pancreatic Cancer

(some of them even survived for a year or more), the overall survival rate has not improved, and the 5-year survival is less than 4\% [Weinberg et al: Oncology (Williston Park) 2015;29: 809-820, 886; Greenlee et al: CA Cancer J Clin 2001;51:15-36; Zhang et al: Gastroenterol Res Pract 2016;2016:8962321]. Hence, it is crucial to develop more effective local treatment strategies for tumor tissue and symptom palliation. At present, endoscopy has gradually become the mainstream method for local treatment of gastrointestinal cancer due to mini-invasiveness and real-time observation. Conventional endoscopy can be used to manage the complication caused by PC, including endoscopic biliary stent placement for obstructive jaundice, and duodenal stent placement for duodenal obstruction. In addition, in those cases in whom obstructive jaundice failed to be relieved by endoscopic biliary stent placement, EUS-guided biliary drainage has emerged as an alternative procedure. Furthermore, antitumor agents can be delivered into tumor tissue or celiac plexus directly under interventional EUS guided to manage the tumor or the pain caused by the tumor. In this review, the progress in conventional endoscopy and EUS for PC management is discussed.

(c) 2016 S. Karger AG, Basel

\section{Endoscopic Ultrasound-Guided Interventional Therapy}

\section{Endoscopic Ultrasound-Guided Brachytherapy}

Endoscopic ultrasound (EUS)-guided radioactive seed implantation has emerged as a novel strategy for the treatment of pancreatic cancer (PC). EUS-guided brachytherapy has proven to be a mini-invasive, simple and safe procedure, using sufficient and durable radiation, and to minimize surrounding normal tissue damage. This technique is feasible and safe for the treatment of PC, and it could also relieve pain due to PC. In 2006, Sun et al. [1] reported that EUS-mediated implantation of ${ }^{125}$ I seeds can be used for patients with locally advanced PC. Fifteen patients with PC were enrolled in this study, and most of the cases are in stage III or IV. During a median of 10.6 months of follow-up, $27 \%$ of patients had partial response and $20 \%$ had minimal response. In a prospective pilot study published by Jin et al. [2], the median survival of 22 patients was 9.0 months, but only 3 had partial remission. In addition, the pain score on the visual analog scale (VAS) decreased 1 week and 1 month after ${ }^{125}$ I seed implantation. Du et al. [3] conducted a study enrolling 100 cases to determine the long-term effects of ${ }^{125} \mathrm{I}$ seed implantation. It showed an estimated median progression-free survival and overall survival of 4.5 and 7.0 months, respectively. Similarly, VAS scores dropped dramatically 1 week after implantation and remained significantly low until the third month. However, all of those studies had only one cohort, and the advantage of this technique needs to be confirmed by comparison studies.

\section{EUS-Guided Fiducial Placement}

Radiation therapy is one of the main treatment methods for unresectable or metastatic PC. However, due to the low-contrast character of soft issue, pancreatic tumors are poorly visible on cone-beam CT. Hence, for allowing precise and real-time tracking of the tumor under the guidance of fiducial markers placed in the tumor tissue, image-guided radiation has become a significant method in PC treatment. Traditionally, fiducials were inserted either surgically or percutaneously under image guidance. As a mini-invasive and visualization approach, EUS-guided fiducial placement has gradually turned into a mainstream treatment. In 2006, Pishvaian et al. [4] used EUS for fiducial placement, and several studies were published to evaluate its safety and feasibility under EUS guidance [5-9]. The technical success rate of this technique was $90-100 \%[5,6,9,10]$. In addition, the complication rate associated with this technique was low, and the tumor migration rate of fiducial markers was 
$7 \%$ [11]. In order to have appropriate tracking, it is recommended to place fiducials with 'ideal fiducial geometry' (IFG) [10]. The main disadvantage of EUS is that it is hard to achieve IFG. However, a recent retrospective study showed that IFG may be unnecessary for successful tracking and delivery of radiation. In this study, 77 patients were enrolled to compare the difference between EUS-guided fiducial placement and surgical placement. Although surgical placement had a higher IFG proportion, the success rate of fiducial tracking used for CyberKnife therapy was similar between the two groups [10]. Therefore, with the merit of mini-invasiveness and little complications, EUS-guided fiducial placement is feasible and safe for PC treatment.

\section{EUS-Guided Fine Needle Injection}

Antitumor agents can be directly delivered into tumor tissue for the treatment of locally advanced PC by EUS-fine needle injection (FNI). Chang et al. [12] were the first to publish a phase I clinical trial study of the usage of antitumor injection for advanced PC. Allogeneic mixed lymphocyte culture was delivered to 8 patients by EUS-FNI. Three of them had partial or minor response, with a median survival of 13.2 months and without procedure-related complications. In a phase I/II trial conducted by Hecht et al. [13], 21 patients with PC received 8 weeks of injections of ONYX-015. After a combination with gemcitabine, 2 patients had partial regression, 2 had minor responses, 6 had stable disease, and 11 had progressive disease or had to quit the study because of treatment toxicity. Complications presented in 4 patients, including sepsis and duodenal perforations. After that, they conducted another phase I/II study on injection TNFerade combined with 5-fluorouracil and radiotherapy for treatment of locally advanced PC [14]. Fifty patients were given EUS-FNI, 1 of them had complete response, 3 partial responses, and 12 stable disease. However, although the feasibility and safety had been confirmed by the above study, until now the long-term efficiency of EUS-FNI is still undefined.

\section{EUS-Guided Radiofrequency Ablation}

The efficacy and safety of percutaneous ultrasound-guided radiofrequency ablation (RFA) for PC have been confirmed. Currently, EUS-RFA has emerged as an alternative procedure. Several studies have reported an animal experiment for normal porcine pancreas $[15,16]$. Recently, Song et al. [17] demonstrated the technical feasibility and safety of EUS-RFA for unresectable PC. This study enrolled 6 patients; 4 patients had stage 3 disease and 2 patients had stage 4 disease. After the procedure, 2 patients experienced mild abdominal pain, but there were no other adverse events such as pancreatitis or bleeding. As expected, 2 patients had mild abdominal pain, and no major complication was noted.

\section{EUS-Guided Ethanol Ablation}

EUS-guided ethanol ablation is a novel treatment strategy for pancreatic cystic neoplasms (PCNs) and pancreatic neuroendocrine tumors. The use of EUS-guided ethanol ablation for pancreatic cystic lesions was first described by Gan et al. [18] in a pilot study including 25 patients. After evacuation of the cyst with needle aspiration, the cyst cavity was lavaged with ethanol for 3-5 min. None of the patients reported any symptoms in the short or long term, and 8 of them had complete resolution of their cyst after 1 year of follow-up. This study suggested that ethanol lavage of pancreatic cystic lesions is safe and feasible. A randomized controlled trial (RCT) study conducted by DeWitt et al. [19] showed that EUS-guided ethanol lavage resulted in a greater mean percentage of decrease in the cyst surface area compared with saline solution alone ( 43 vs. 11\%), and 12 of 36 PCNs showed complete resolution. Longterm follow-up data also suggested that ethanol ablation had a durable, image-defined resolution [20]. Oh et al. [21] reported an experiment to evaluate the usage of EUS-guided injection 
and lavage of ethanol, followed by injection of paclitaxel for PCNs. One year later, $62 \%$ of the PCNs showed complete resolution without complication, which demonstrated that ethanol lavage combined with paclitaxel injection may be more effective. EUS-guided ethanol ablation is also used for the management of pancreatic solid tumors. Recently, Park et al. [22] investigated the safety, feasibility, and treatment response after EUS-guided ethanol injection for small pancreatic neuroendocrine tumors. EUS-guided ethanol injection was successfully performed in 11 patients with 14 tumors. Ten patients underwent clinical follow-up after treatment. After 3 months of follow-up, a single treatment session resulted in complete responses for 7 of 13 (53.8\%).

\section{EUS-Guided Celiac Plexus Neurolysis}

Pain is the most common complication in patients with PC and difficult to treat in clinical practice. Traditionally, this symptom was alleviated by opioid analgesics. However, these medications usually lead to serious side effects, including sedation, chronic constipation, delirium, nausea, vomiting, and a negative impact on quality of life [23]. In order to overcome these disadvantages, Wiersema and Wiersema [24] described the treatment method of EUSguided celiac plexus neurolysis (EUS-CPN) for PC pain in 1996. A meta-analysis including 119 patients showed that the effective rate of EUS-CPN to alleviate abdominal pain was $72.54 \%$ in patients with PC [25]. Another meta-analysis conducted by Arcidiacono et al. [26] identified a difference in efficacy between CPN and opioid consumption. Compared with opioid consumption, EUS-CPN was demonstrated to reduce pain after the fourth and eighth week, which consequently significantly reduced opioid consumption. In fact, EUS-CPN may increase the survival of patients with PC. In a case-control study conducted by Fujii-Lau et al. [27], EUS-CPN was associated with longer survival compared with non-EUS approaches. However, instead of completely eliminating the pain, EUS-CPN can only relieve pain to a certain degree, and the majority of patients still needs opioid drugs. In addition, this technique also has some adverse events, and the adverse event rate related to EUS-CPN was about 30\% [11]. The most common adverse events are diarrhea, abdominal pain and hypotension. Other serious adverse events are bleeding, abscess, abdominal ischemia, permanent paralysis as well as death. Therefore, to increase the efficacy and safety of EUS-CPN, different kinds of techniques were conducted. In 2011, an RCT study reported that there was no difference in the onset or duration of pain relief when either 1 or 2 injections were used [28]. However, EUS-guided direct celiac ganglia neurolysis may be superior to conventional EUS-CPN in cancer pain relief [29]. The study by Doi et al. [30] showed that the positive and complete response rates were significantly higher in the EUS-guided direct celiac ganglia neurolysis group than in the EUS-CPN group. However, all of these studies have small sample sizes. Therefore, a largesample study should be carried out to define these controversies and evaluate the efficacy and safety of those techniques.

CPN can only relieve pain to a limited degree, with a short duration, and the analgesic effect is inversely correlated with the extent of invasion of celiac ganglia [31]. Therefore, a series of novel approaches were conducted to improve this technique. In 2012, Wang et al. [32] implanted ${ }^{125}$ I around the celiac ganglia with EUS guidance and found that EUS-guided

direct celiac ganglion irradiation with ${ }^{125}$ I seeds can reduce the VAS score and analgesic drug consumption in patients with unrespectable PC. Recently, a case report was published by Jin et al. [33] describing a patient with uncontrolled pain caused by advanced PC who received EUS-RFA. An RF probe was inserted into the center of the celiac ganglion and fixed RF power (heating) with $10 \mathrm{~W}$ for $120 \mathrm{~s}$ and $15 \mathrm{~W}$ for $120 \mathrm{~s}$. After 2 days, the VAS score decreased from 8 to 2 . Two weeks after the procedure, the VAS score stabilized at 4, and opioid analgesics were still not needed. Additional larger studies are warranted to establish this as an acceptable option for pain relief of inoperable PC. 


\section{EUS-Guided Biliary Drainage}

Most of the patients with PC, especially tumors in the pancreatic head area, present bile duct obstruction. On those occasions, endoscopic retrograde cholangiopancreatography (ERCP) is the preferred procedure for biliary drainage. However, about $3-10 \%$ of the cases cannot be managed by ERCP due to complete tumor obstruction of the distal common bile duct and papilla invasion [34, 35]. Recently, EUS-guided biliary drainage has emerged as an alternative procedure for relieving biliary obstruction in cases in which ERCP has failed. EUSguided biliary drainage broadly includes EUS-guided rendezvous technique, EUS-guided choledochoduodenostomy, EUS-guided hepaticogastrostomy, EUS-guided antegrade stenting, and EUS-guided gallbladder drainage [36-40]. A system review conducted by our group has recently shown that the technical success rate and functional success rate of EUS-guided biliary drainage for malignant obstruction were 94.55 and $92.49 \%$, respectively [41]. However, data regarding the efficacy and safety of this technique for unresectable PC are lacking. Most studies are case reports or case series [35, 37, 42-44]. Therefore, the next step is to conduct large-sample studies to evaluate the efficacy and safety of EUS-guided biliary drainage for unresectable PC.

\section{Endoscopic Biliary Stenting for Obstructive Jaundice}

$80 \%$ of patients with PC will suffer from obstructive jaundice and may require biliary drainage either preoperatively or merely for palliation [45]. Currently, endoscopic biliary stenting still is the preferred strategy, because it is minimally invasive [46-48]. Since 1980, plastic stents have been widely used for endoscopic relief of malignant biliary obstruction [49]. Because of the large diameter, metal stents may be better than plastic stents in the long term and less susceptible to occlusion. At present, there are numerous studies comparing the use of plastic versus metal stents in the population with PC. They are equally effective for the relief of malignant obstructive jaundice, with both showing a technical success rate of $>90 \%$ [50]. However, metal stents have a higher safety rate than plastic stents. The study by Adams et al. [51] found that the complication rate of plastic stents was almost 7 times higher than that of metal stents, and the rate of hospitalization for stent-related complications was 3-fold higher in the plastic stent group than in the metal stent group. Moreover, the study by Tol et al. [52] showed that for resectable PC, both preoperative biliary drainage-related and stentrelated complication rates were smaller in the metal stent group than in the plastic stent group ( 24 vs. 46 , and 6 vs. $31 \%$, respectively). The above data suggest that metal stents yield a better outcome compared with plastic stents. However, metal stents are also more expensive, which should be considered in clinical application. Recently, Walter et al. [53] conducted an RCT to evaluate which type of stent, either a plastic or self-expandable metal stents (SEMS), is superior for the palliation of malignant extrahepatic bile duct obstruction with regard to clinical effects and associated costs, both in patients with a short and long survival time. They found that the functional stent times of SEMS are longer compared with those of plastic stents (288 vs. 172 days), and although the SEMS placement leads to higher costs, the total costs are not different between both stent types. Therefore, metal stents are the preferred option for all patients with malignant extrahepatic bile duct obstruction.

Besides the traditional stent placement for the palliation of obstructive jaundice, radioactive stent placement is a novel strategy. To date, few studies have evaluated the efficacy and safety of radioactive stents. In 2007, Yan et al. [54] published an animal experiment for the usage of radioactive stents in PC. The procedures were successfully performed on all pigs without perforation of the common bile duct wall. Next, a pilot study was published by Liu et al. [55], in which a total of 16 radioactive stents were successfully placed in 11 patients, 
without life-threatening complications. After 2 months of follow-up, 8 patients $(72.7 \%)$ showed stable disease, whereas 3 patients $(27.3 \%)$ showed progressive disease. Liu et al. were the first to demonstrate that radioactive stent placement for palliative treatment is effective and safe. Recently, a study compared the difference between the irradiation stent and the conventional stent for biliary obstruction [56]. The stents were successfully placed in 23 patients, and obstructive jaundice was relieved in all patients except 3 in the control group. The median and mean overall survival rates were higher in patients with an irradiation stent than in those with a conventional biliary stent, and the irradiation stent group has a longer stent patent time. However, all the above studies only included small simple sizes. Therefore, the efficacy and safety of radioactive stent placement needs further investigation.

\section{Endoscopic Duodenal Stent Placement}

About $10-25 \%$ of patients with PC developed malignant duodenal outlet obstruction [57, 58]. However, this rate increased to $38 \%$ because of the advances in diagnosing duodenal outlet obstruction with imaging and endoscopy as well as treatment with chemoradiation [59]. As first described by Topazian et al. [60], the duodenal SEMS placement has become the first choice for the palliation of duodenal obstruction due to minimal invasiveness. Compared with surgical gastroenterostomy, endoscopic SEMS placement has a higher clinical success rate, a shorter procedure time until starting oral intake, less morbidity, a lower incidence of delayed gastric emptying, and a shorter time of hospitalization [61]. In order to achieve the best clinical outcome of SEMS placement, the principal element is choosing the appropriate type of stent according to the tumor type, the stricture site and morphology. Woo et al. [62] showed that although the technical and clinical success rates were similar, uncovered SEMS present a lower complication rate than the covered group for the treatment of malignant duodenal obstruction caused by pancreaticobiliary (34.8 vs. $62.5 \%$ ).

In conclusion, with the development of the endoscopic technology, endoscopy-guided interventional therapy has played an important role in PC treatment from tumor killing to pain relief and drainage with minimal invasiveness. However, there are still some deficiencies, and more studies should be conducted to improve the efficacy of endoscopy-guided interventional therapy.

\section{Disclosure Statement}

The authors have nothing to declare.

\section{References}

1 Sun S, Xu H, Xin J, Liu J, Guo Q, Li S: Endoscopic ultrasound-guided interstitial brachytherapy of unresectable pancreatic cancer: results of a pilot trial. Endoscopy 2006;38:399-403.

-2 Jin Z, Du Y, Li Z, Jiang Y, Chen J, Liu Y: Endoscopic ultrasonography-guided interstitial implantation of iodine 125-seeds combined with chemotherapy in the treatment of unresectable pancreatic carcinoma: a prospective pilot study. Endoscopy 2008;40:314-320.

3 Du Y, Jin Z, Meng H, Zou D, Chen J, Liu Y, et al: Long-term effect of gemcitabine-combined endoscopic ultrasonography-guided brachytherapy in pancreatic cancer. J Interv Gastroenterol 2013;3:18-24.

-4 Pishvaian AC, Collins B, Gagnon G, Ahlawat S, Haddad NG: EUS-guided fiducial placement for CyberKnife radiotherapy of mediastinal and abdominal malignancies. Gastrointest Endosc 2006;64:412-417.

5 Davila Fajardo R, Lekkerkerker SJ, van der Horst A, Lens E, Bergman JJ, Fockens P, et al: EUS-guided fiducial markers placement with a 22-gauge needle for image-guided radiation therapy in pancreatic cancer. Gastrointest Endosc 2014;79:851-855. 
6 Choi JH, Seo DW, Park do H, Lee SK, Kim MH: Fiducial placement for stereotactic body radiation therapy under only endoscopic ultrasonography guidance in pancreatic and hepatic malignancy: practical feasibility and safety. Gut Liver 2014;8:88-93.

7 Park WG, Yan BM, Schellenberg D, Kim J, Chang DT, Koong A, et al: EUS-guided gold fiducial insertion for imageguided radiation therapy of pancreatic cancer: 50 successful cases without fluoroscopy. Gastrointest Endosc 2010;71:513-518.

-8 Sanders MK, Moser AJ, Khalid A, Fasanella KE, Zeh HJ, Burton S, et al: EUS-guided fiducial placement for stereotactic body radiotherapy in locally advanced and recurrent pancreatic cancer. Gastrointest Endosc 2010;71: 1178-1184.

-9 Varadarajulu S, Trevino JM, Shen S, Jacob R: The use of endoscopic ultrasound-guided gold markers in imageguided radiation therapy of pancreatic cancers: a case series. Endoscopy 2010;42:423-425.

10 Majumder S, Berzin TM, Mahadevan A, Pawa R, Ellsmere J, Sepe PS, et al: Endoscopic ultrasound-guided pancreatic fiducial placement: how important is ideal fiducial geometry? Pancreas 2013;42:692-695.

-11 Fabbri C, Luigiano C, Lisotti A, Cennamo V, Virgilio C, Caletti G, et al: Endoscopic ultrasound-guided treatments: are we getting evidence based - a systematic review. World J Gastroenterol 2014;20:8424-8448.

12 Chang KJ, Nguyen PT, Thompson JA, Kurosaki TT, Casey LR, Leung EC, et al: Phase I clinical trial of allogeneic mixed lymphocyte culture (cytoimplant) delivered by endoscopic ultrasound-guided fine-needle injection in patients with advanced pancreatic carcinoma. Cancer 2000;88:1325-1335.

13 Hecht JR, Bedford R, Abbruzzese JL, Lahoti S, Reid TR, Soetikno RM, et al: A phase I/II trial of intratumoral endoscopic ultrasound injection of ONYX-015 with intravenous gemcitabine in unresectable pancreatic carcinoma. Clin Cancer Res 2003;9:555-561.

$>14$ Hecht JR, Farrell JJ, Senzer N, Nemunaitis J, Rosemurgy A, Chung T, et al: EUS or percutaneously guided intratumoral TNFerade biologic with 5-fluorouracil and radiotherapy for first-line treatment of locally advanced pancreatic cancer: a phase I/II study. Gastrointest Endosc 2012;75:332-338.

15 Goldberg SN, Mallery S, Gazelle GS, Brugge WR: EUS-guided radiofrequency ablation in the pancreas: results in a porcine model. Gastrointest Endosc 1999;50:392-401.

16 Gaidhane M, Smith I, Ellen K, Gatesman J, Habib N, Foley P, et al: Endoscopic ultrasound-guided radiofrequency ablation (EUS-RFA) of the pancreas in a porcine model. Gastroenterol Res Pract 2012;2012:431451.

17 Song TJ, Seo DW, Lakhtakia S, Reddy N, Oh DW, Park do H, et al: Initial experience of EUS-guided radiofrequency ablation of unresectable pancreatic cancer. Gastrointest Endosc 2016;83:440-443.

-18 Gan SI, Thompson CC, Lauwers GY, Bounds BC, Brugge WR: Ethanol lavage of pancreatic cystic lesions: initial pilot study. Gastrointest Endosc 2005;61:746-752.

19 DeWitt J, McGreevy K, Schmidt CM, Brugge WR: EUS-guided ethanol versus saline solution lavage for pancreatic cysts: a randomized, double-blind study. Gastrointest Endosc 2009;70:710-723.

20 Dewitt J, Dimaio CJ, Brugge WR: Long-term follow-up of pancreatic cysts that resolve radiologically after EUSguided ethanol ablation. Gastrointest Endosc 2010;72:862-866.

-21 Oh HC, Seo DW, Song TJ, Moon SH, Park do H, Soo Lee S, et al: Endoscopic ultrasonography-guided ethanol lavage with paclitaxel injection treats patients with pancreatic cysts. Gastroenterology 2011;140:172-179.

22 Park do H, Choi JH, Oh D, Lee SS, Seo DW, Lee SK, et al: Endoscopic ultrasonography-guided ethanol ablation for small pancreatic neuroendocrine tumors: results of a pilot study. Clin Endosc 2015;48:158-164.

-23 Eriksen J, Sjogren P, Bruera E, Ekholm 0, Rasmussen NK: Critical issues on opioids in chronic non-cancer pain: an epidemiological study. Pain 2006;125:172-179.

24 Wiersema MJ, Wiersema LM: Endosonography-guided celiac plexus neurolysis. Gastrointest Endosc 1996;44: 656-662.

25 Kaufman M, Singh G, Das S, Concha-Parra R, Erber J, Micames C, et al: Efficacy of endoscopic ultrasound-guided celiac plexus block and celiac plexus neurolysis for managing abdominal pain associated with chronic pancreatitis and pancreatic cancer. J Clin Gastroenterol 2010;44:127-134.

26 Arcidiacono PG, Calori G, Carrara S, McNicol ED, Testoni PA: Celiac plexus block for pancreatic cancer pain in adults. Cochrane Database Syst Rev 2011;3:CD007519.

-27 Fujii-Lau LL, Bamlet WR, Eldrige JS, Chari ST, Gleeson FC, Abu Dayyeh BK, et al: Impact of celiac neurolysis on survival in patients with pancreatic cancer. Gastrointest Endosc 2015;82:46-56.e2.

28 LeBlanc JK, Al-Haddad M, McHenry L, Sherman S, Juan M, McGreevy K, et al: A prospective, randomized study of EUS-guided celiac plexus neurolysis for pancreatic cancer: one injection or two? Gastrointest Endosc 2011; 74:1300-1307.

-29 Ascunce G, Ribeiro A, Reis I, Rocha-Lima C, Sleeman D, Merchan J, et al: EUS visualization and direct celiac ganglia neurolysis predicts better pain relief in patients with pancreatic malignancy (with video). Gastrointest Endosc 2011;73:267-274.

-30 Doi S, Yasuda I, Kawakami H, Hayashi T, Hisai H, Irisawa A, et al: Endoscopic ultrasound-guided celiac ganglia neurolysis vs celiac plexus neurolysis: a randomized multicenter trial. Endoscopy 2013;45:362-369.

-31 Jin Z, Chang KJ: Endoscopic ultrasound-guided fiducial markers and brachytherapy. Gastrointest Endosc Clin N Am 2012;22:325-331, x.

-32 Wang KX, Jin ZD, Du YQ, Zhan XB, Zou DW, Liu Y, et al: EUS-guided celiac ganglion irradiation with iodine-125 seeds for pain control in pancreatic carcinoma: a prospective pilot study. Gastrointest Endosc 2012;76:945952. 
-33 Jin ZD, Wang L, Li Z: Endoscopic ultrasound-guided celiac ganglion radiofrequency ablation for pain control in pancreatic carcinoma. Dig Endosc 2015;27:163-164.

-34 Ekkelenkamp VE, de Man RA, Ter Borg F, Borg PC, Bruno MJ, Groenen MJ, et al: Prospective evaluation of ERCP performance: results of a nationwide quality registry. Endoscopy 2015;47:503-507.

-35 Artifon EL, Takada J, Okawa L, Moura EG, Sakai P: EUS-guided choledochoduodenostomy for biliary drainage in unresectable pancreatic cancer: a case series. JOP 2010;11:597-600.

-36 Seewald S, Groth S, Omar S, Imazu H, Seitz U, De Weerth A, et al: Aggressive endoscopic therapy for pancreatic necrosis and pancreatic abscess: a new safe and effective treatment algorithm (videos). Gastrointest Endosc 2005;62:92-100.

-37 Baron TH, DeSimio TM: New ex-vivo porcine model for endoscopic ultrasound-guided training in transmural puncture and drainage of pancreatic cysts and fluid collections (with videos). Endosc Ultrasound 2015;4: 34-39.

38 Paik WH, Park DH, Choi JH, Choi JH, Lee SS, Seo DW, et al: Simplified fistula dilation technique and modified stent deployment maneuver for EUS-guided hepaticogastrostomy. World J Gastroenterol 2014;20:50515059.

39 Hara K, Yamao K, Hijioka S, Mizuno N, Imaoka H, Tajika M, et al: Prospective clinical study of endoscopic ultrasound-guided choledochoduodenostomy with direct metallic stent placement using a forward-viewing echoendoscope. Endoscopy 2013;45:392-396.

40 Weilert F: Prospective evaluation of simplified algorithm for EUS-guided intra-hepatic biliary access and anterograde interventions for failed ERCP. Surg Endosc 2014;28:3193-3199.

-41 Vilmann P, Hancke S, Pless T, Schell-Hincke JD, Henriksen FW: One-step endosonography-guided drainage of a pancreatic pseudocyst: a new technique of stent delivery through the echo endoscope. Endoscopy 1998;30: 730-733.

-42 Nelsen EM, Johnson EA, Walker AJ, Pfau P, Gopal DV: Endoscopic ultrasound-guided pancreatic pseudocyst cystogastrostomy using a novel self-expandable metal stent with antimigration system: a case series. Endosc Ultrasound 2015;4:229-234.

43 Itoi T, Itokawa F, Tsuchiya T, Tsuji S, Tonozuka R: Endoscopic ultrasound-guided choledochoantrostomy as an alternative extrahepatic bile duct drainage method in pancreatic cancer with duodenal invasion. Dig Endosc 2013;25(suppl 2):142-145.

-44 Widmer J, Alvarez P, Gaidhane M, Paddu N, Umrania H, Sharaiha R, et al: Endoscopic ultrasonography-guided cholecystogastrostomy in patients with unresectable pancreatic cancer using anti-migratory metal stents: a new approach. Dig Endosc 2014;26:599-602.

45 Toki MI, Syrigos KN, Saif MW: The role of biliary drainage in patients with pancreatic adenocarcinoma. JOP 2014;15:128-131.

46 Murakami M, Shimizu J, Kim Y, Kim HM, Souma Y, Hirota M, et al: Bypass surgery or stent placement for biliary obstruction in patients with unresectable pancreatic cancer. Gan To Kagaku Ryoho 2013;40:1705-1707.

47 Yamamoto R, Takahashi M, Osafune Y, Chinen K, Kato S, Nagoshi S, et al: Comparison of endoscopic stenting for malignant biliary obstruction: a single-center study. World J Gastrointest Endosc 2015; 7:889-894.

$\checkmark 48$ Kofokotsios A, Papazisis K, Andronikidis I, Ntinas A, Kardassis D, Vrochides D: Palliation with endoscopic metal stents may be preferable to surgical intervention for patients with obstructive pancreatic head adenocarcinoma. Int Surg 2015;100:1104-1110.

49 Baron TH, Grimm IS: Relief of obstructive jaundice from pancreatic cancer: the end of the plastic stent era? Gut 2016;65:191-192.

50 Grimm IS, Baron TH: Biliary stents for palliation of obstructive jaundice: choosing the superior endoscopic management strategy. Gastroenterology 2015;149:20-22.

-51 Adams MA, Anderson MA, Myles JD, Khalatbari S, Scheiman JM: Self-expanding metal stents (SEMS) provide superior outcomes compared to plastic stents for pancreatic cancer patients undergoing neoadjuvant therapy. J Gastrointest Oncol 2012;3:309-313.

52 Tol JA, van Hooft JE, Timmer R, Kubben FJ, van der Harst E, de Hingh IH, et al: Metal or plastic stents for preoperative biliary drainage in resectable pancreatic cancer. Gut 2015, Epub ahead of print.

53 Walter D, van Boeckel PG, Groenen MJ, Weusten BL, Witteman BJ, Tan G, et al: Cost efficacy of metal stents for palliation of extrahepatic bile duct obstruction in a randomized controlled trial. Gastroenterology 2015;149: 130-138.

54 Yan L, Jun-Lou L, Zhen-Zhai C, Zheng L, Yuan-Hang D, Zhao-Shen L, et al: A novel approach for treatment of unresectable pancreatic cancer: design of radioactive stents and trial studies on normal pigs. Clin Cancer Res 2007;13:3326-3332.

55 Liu Y, Lu Z, Zou DW, Jin ZD, Liu F, Li SD, et al: Intraluminal implantation of radioactive stents for treatment of primary carcinomas of the peripancreatic-head region: a pilot study. Gastrointest Endosc 2009;69:10671073.

56 Zhu HD, Guo JH, Zhu GY, He SC, Fang W: A novel biliary stent loaded with (125)I seeds in patients with malignant biliary obstruction: preliminary results versus a conventional biliary stent. J Hepatol 2012;56: 1104-1111.

57 Warshaw AL, Swanson RS: Pancreatic cancer in 1988. Possibilities and probabilities. Ann Surg 1988;208: 541-553. 
58 Watanapa P, Williamson RCN: Surgical palliation for pancreatic cancer: developments during the past two decades. Br J Surg 1992;79:8-20.

59 Shah A, Fehmi A, Savides TJ: Increased rates of duodenal obstruction in pancreatic cancer patients receiving modern medical management. Dig Dis Sci 2014;59:2294-2298.

-60 Topazian M, Ring E, Grendell J: Palliation of obstructing gastric cancer with steel mesh, self-expanding endoprostheses. Gastrointest Endosc 1992;38:58-60.

61 Hosono S, Ohtani H, Arimoto Y, Kanamiya Y: Endoscopic stenting versus surgical gastroenterostomy for palliation of malignant gastroduodenal obstruction: a meta-analysis. J Gastroenterol 2007;42:283-290.

-62 Woo SM, Kim DH, Lee WJ, Park KW, Park SJ, Han SS, et al: Comparison of uncovered and covered stents for the treatment of malignant duodenal obstruction caused by pancreaticobiliary cancer. Surg Endosc 2013;27: 2031-2039. 